\title{
The Evaluation of East Asian Regionalism from APEC to RCEP*
}

\author{
Inkyo Cheong ${ }^{* *}$, Jungran Cho***
}

\begin{abstract}
Building a large trading bloc tends to produce substantial economic gains, while minimizing economic losses from overlapping FTAs. East Asia has tried to generate the impetus for promoting region-wide trading blocs, but most of those blocs have been overlapped and multilayered. This paper reviews the evolution of East Asian regionalism from the APEC FTA under the 1994 Bogor Goal to recent RCEP promoted in 2013. This paper underlines that the continued expansion of multilayered trading blocs in East Asia works as a serious obstacle to regional economic integration, rather than exploring the realization of a region-wide trading bloc.
\end{abstract}

Keywords : Overlapping FTAs, East Asian Vision Group (EAVG), APEC FTA, East Asian Community (EAC)

JEL classification Numbers : F13, F15, F16

* This work was supported by a National Research Foundation of Korea Grant which was funded by the Korean Government (MOEHRD) (NRF-2011-413-B00008) as well as by the Research Grant of the Inha University. To whom correspondence should be addressed. E-mail: jungran@inha.ac.kr

** Professor, Department of Economics, Inha University

*** Research Fellow, JRI, Inha University 


\section{Introduction}

Economic cooperation body East Asian countries promoted for the first time is the Asia-Pacific Economic Cooperation (APEC) in 1989. APEC agreed to introduce the APEC FTA in the 1994 APEC Leaders' Meeting. In recent years, East Asia has witnessed the declaration of various region-wide economic integration initiatives, including the FTA in the Asia-Pacific region (FTAAP), the ASEAN+1 FTAs, the East Asian FTA, the Comprehensive Economic Partnership for East Asia (CEPEA), the Trans-Pacific Partnership Agreement (TPP), the China-Japan-Korea (CJK) FTA, and the Regional Comprehensive Economic Partnership (RCEP).

Several tentative observations can be made about the emergence of the initiatives for these large-scale trading blocs in East Asia. First, the initiatives for regional economic integration have broadened regionally and the level of political engagement has increased. Second, East Asian regionalism has progressed over time, but the prospect for a region-wide trading bloc in East Asia is not very optimistic. Third, from the theory of economic integration, the Spaghetti Bowl losses could be worried because these FTAs overlap with different rules of origin. Finally, ASEAN maintain its centrality in promoting East Asian economic integration.

Any assessment of the realizable possibility and economic feasibility of a region-wide FTA has to come before discussing the establishment of a regional economic community. An economic community means the state or process in which multiple countries abolish trade barriers through an institutional agreement and establish a system through which a community can establish and govern major policies as a transnational entity, including those on market access, trade rules, finance, banking, and currency, depending on the stage of integration. The fact that East Asian countries have promoted various formats of large trading blocs can be regarded as a contribution to the achievement of the East Asian Community in the long run. Recent proposals for various approaches to region-wide FTAs such as the RCEP can be associated with the long-term goal of the EAC, but large blocs have changed the titles of the blocs without exploring the contents.

That is, East Asian countries have promoted multilayered regionalism. Though there are many issues surrounding East Asian regionalism, including some controversy over the perception of history, this paper reviews the evolution of East Asian regionalism from the APEC FTA under the 1994 Bogor Goal to recent RCEP promoted in 2013. If no leadership is created, the RCEP may end up like the APEC FTA. This paper underlines that the continued expansion of multilayered trading blocs in East Asia works as a serious obstacle to regional economic integration, rather than exploring the realization of a region-wide 
trading bloc. Finally, this paper tries to analyze the prospect for East Asian regionalism. This paper starts with the analysis of APEC regionalism under the APEC process.

\section{Recollection of APEC}

In 1989, ministerial-level officials from 12 countries (the U.S., Australia, Canada, New Zealand, Japan, Korea, and six ASEAN countries) held an unofficial meeting in Canberra, Australia, and agreed to the launch of the Asia-Pacific Economic Cooperation (APEC). Afterward, at the 3rd Seoul Conference in 1991, China, Taiwan, and Hong Kong joined, followed by Mexico and Papua New Guinea at the 1993 Seattle Conference and Chile in 1994, Russia, Vietnam and Peru in 1998. As a result, APEC currently has 21 members.

The 1993 Seattle Conference was upgraded to the summit level, and in 1994, with the coming of the Bogor Declaration (which meant the trade liberalization of the APEC region), there was an expectation that APEC would develop into an economic integration body comparable to the E.U. in Europe and NAFTA in North America. In addition, the GDP of APEC accounted for almost $60 \%$ of the world's GDP and $50 \%$ of world trade, and therefore, intra-regional free trade was expected to be achieved by 2010 (2020 for developing countries). In this regard, APEC countries were expected to realize substantial economic gains through region-wide trade liberalization and cope with the expansion of regionalism at the global level.

However, APEC's optimistic expectations collapsed with its failure to play a major role in the Asian financial crisis of 1997, and with the U.S. interest in APEC weakening, its status weakened to "all talk." Worse, although advanced economies' Bogor Declaration deadline was tightly set to 2010, there was no country willing to implement it following the Bogor Declaration, and therefore APEC failed to lead member countries to fulfill the goal of liberalization. Japan, which chaired APEC in 2010, once proposed a scheme for realizing the APEC liberalization of free trade, and the U.S., which chaired it 2011, once commented on fulfilling the FTAAP by expanding and developing the TPP. However, it is known that the U.S. has no intention to invite China to the TPP.1)

Contrary to initial expectations, the weakening of expectations for APEC and its role was due to the absence of a country that could coordinate diverse opinions of APEC's 21 member economies in addition to inherent obstacles in terms of institutional factors such as completely institution-based decision-making procedures, open regionalism, and

1) For further details, see Armstrong (2011). 
nonbinding voluntarism. No leadership by advanced economies has made. From the very beginning, the U.S. participated in APEC to prevent economic cooperation solely by East Asian countries in the 1990s, and even Japan rejected the Early Voluntary Sectional Liberalization (EVSL), which was part of APEC's liberalization efforts. Open regionalism here the word "open" in open regionalism refers to the extension of APEC's trade liberalization benefits to non-member countries, and the word "regionalism," to the establishment of a preferential (closed) trade bloc - was established as the most important principle of APEC, but in reality, it became the biggest obstacle to APEC development.

APEC had no a mechanism for promoting internal trade liberalization but adopted an unrealistic principle, although the term "open regionalism" could be interpreted in various ways. ${ }^{2)}$ APEC development became increasingly difficult by the increase in the number of member countries and APEC's failure to establish realistic systems and institutions for promoting internal liberalization and enabling the Bogor goals. In addition, with the inclusion of diverse issues such as terrorism, corruption, and women's rights in addition to its initial goals, APEC's dynamism weakened over time. Although the APEC Summit is held in October or November every year and its declaration is made, it has received relatively little attention from the global community.

The U.S. may regard East Asian economic integration as a way to obtain its presence in East Asia, and there are political factors preventing the U.S. from sharing common interests in APEC with China. In addition, Japan is likely to take the same position as the U.S. regarding China. The U.S. has participated in APEC to prevent it from developing into a vehicle for cooperation solely among East Asian countries. Similarly, the fact that the U.S. has participated in the East Asian Summit during the recent years may be explained with its reason for participating in APEC in the past. ${ }^{3)}$ Regional expansion has become a serious barrier to regional economic integration. That is, no country can coordinate the diverse positions raised by ASEAN, China, Japan, and the U.S. through the East Asian Summit and APEC. The more the stakeholders in East Asian regionalism, the weaker the foundation is for regional economic integration in East Asia.

2) For a constructive interpretation of open regionalism, see Garnaut (1994, 1996), Bergsten (1997) and Sutton (2007).

3) At a press conference during the 2009 ASEAN Region Security Forum in Phuket, Thailand, Secretary of State Hillary Clinton repeated the word "partner" in reference to ASEAN a total of nine times in her interview lasting only 6 minutes and 30 seconds and clarified that the U.S. would establish the Diplomacy Representative Office to link Washington with ASEAN, declaring that the U.S. was returning to Southeast Asia. This marked a dramatic turnaround from the previous Bush administration. 


\section{Progress of East Asian Economic Integration and Major Initiatives}

\section{Activities of the East Asian Vision Group}

The master plan for East Asian economic integration originates from a report released in 2001 by the East Asian Vision Group (EAVG, 2001). The 2001 ASEAN+3 Summit talks adopted a phase-in economic integration promotion scheme setting the establishment of the EAVG-proposed East Asian Economic community as a long-term goal while setting an East Asian FTA as a medium-term goal. Since the release of the EAVG report, the discussion on intra-regional economic integration has progressed both officially or unofficially through various channels in East Asia.

The discussion on intra-regional economic cooperation at the ASEAN+3(6) and East Asian Summit talks has featured the elements proposed in the EAVG report. In the decade since the report, the environment for economic integration in the region has changed substantially. The number of countries involved increased from $13($ ASEAN+3) to 16 $(A S E A N+6)$ and then to 18 (ASEAN+8), where "3" refers to CJK in Northeast Asia; "6," to CJK plus Australia, New Zealand, and India; and "8," to ASEAN+6 plus the U.S. and Russia in the East Asian Summit. The region has witnessed the conclusion of many bilateral FTAs. For the promotion of economic integration under recent developments in the environment, the 2nd EAVG report (EAVG II), under consideration since October 2011, was submitted to the ASEAN+3 Summit in 2012. The EAVG II report suggests a plan for realizing the East Asian Community, which is considered to be the ultimate goal of East Asian economic integration. ${ }^{4}$ ) The ASEAN+3 leaders have shared a common perception that it is necessary to make efforts to enhance connectivity to resolve the development gap between countries, which has been a major obstacle to the development of East Asian countries into a single economic region and the reinforcement of intra-regional cooperation, and adopted the "ASEAN+3 Partnership Declaration on Connectivity" for this purpose. ${ }^{5)}$

The adoption of the EAVG II report has become the impetus for taking the discussion on East Asian economic integration to the next level at the East Asian Summit talks in 2012. At the 15th ASEAN+3 Summit talks in 2012, the 10 ASEAN countries and CJK

\footnotetext{
4) Note that the word "Community" is capitalized in EAVG II, whereas it was not in the EAVG (2001). This implies the stronger intention to promote the economic community, although the shape of the East Asia Community remains to be clearly defined in the future.

5) The RCEP covers ASEAN+6 countries, but the negotiations for the RCEP were declared at the ASEAN+3 Leaders' Summit.
} 
leaders checked the status of economic cooperation and regional development and discussed major issues such as food security, financial crises, and economic integration and the direction of ASEAN+3 economic cooperation. The ASEAN+3 leaders celebrated the 15th anniversary of the launch of the ASEAN+3 system in 2012 and assessed that the ASEAN+3 cooperative system, launched in 1997, has agreed to promote East Asian cooperation in about 20 fields, including finance, agriculture, health, culture, and education. In addition, the ASEAN +3 processes have served as a basis for promoting region-wide economic integration such as the RCEP.

\section{CJK FTA and RCEP: Recent Initiatives}

The 2012 East Asian Summit talks declared the initiation of negotiations for the RCEP and the CJK FTA. During the decade since the EAVG report, East Asian countries have concluded many bilateral FTAs and ASEAN+1 FTAs such as the ASEAN-Korea FTA and promoted region-wide FTAs in Northeast Asia and East Asia. It is meaningful to start such a new challenge with the anticipation of the appearance of new leaders from all three countries, namely China, Japan, and Korea.

The RCEP is basically an extension of CEPEA, which has been discussed under Japan's leadership. This actually refers to an FTA between ASEAN+6 countries. In terms of the name, the RCEP can be a stronger and more comprehensive agreement than regular FTAs, but it is very likely that narrowly defined tariff concessions may be drawn in intra-regional trade liberalization. Trade agreements with modified names such as the Economic Partnership Agreement (EPA), the Comprehensive Economic Partnership Agreement (CEPA), and the Economic Cooperation Framework Agreement (ECFA) share a common feature, namely a narrow range of market opening. The RCEP assumes the form of an East Asian FTA in which positions of Japan and ASEAN are reflected, whereas the CJK FTA was initiated with the proposal by China. In accordance with the simultaneous promotion of the CJK FTA and RCEP negotiations, the issue of how these giant FTAs can be promoted harmoniously is an important agenda for East Asian countries.

The discussion on a region-wide FTA in East Asia has been elevated to the government level, but it remains unclear whether government-level negotiations can be promoted in detail within a reasonable period of time because China and Japan have different views on the membership of participating countries in the newly integrated body. In addition, it is not easy to draw a meaningful agreement because there is a large development gap between ASEAN countries and China, Japan, and Korea. The ASEAN framework for the RCEP suggested at the 2011 ASEAN Summit includes various 
negotiation principles, including measures for the preferential treatment of less developed ASEAN countries, different approaches to tariff concessions for goods, and special considerations for services and investment, among others, but it may be difficult for China, Japan, and Korea to agree to a framework wanted by ASEAN while allowing for ASEAN's centrality.

From the perspective of regional economic integration, East Asia is likely to have difficulty promoting two large trade agreements simultaneously. This policy goal of China, Japan, and Korea raises the question of why, if the RCEP is feasible, these countries are promoting the CJK FTA? Is the CJK FTA designed to serve as an alternative if the RCEP fails? Then is the CJK FTA feasible?

During the promotion of the CJK FTA, a major task is to draw an agreement on the negotiation modality of the FTA. The speed of negotiations will vary according to this modality, and the trilateral negotiation is likely to be a difficult process without an agreement on bilateral negotiations between these three countries. However, bilateral negotiations are not likely to be concluded within a short period of time. On the other hand, any trilateral FTA requires the common negotiation modality and elements, but the absence of bilateral negotiations can serve as an obstacle to trilateral negotiations because they are fundamentally based on the bilateral give-and-take principle. The discussion on the CJK FTA was initiated by representative research institutions of the three countries in 2000, and the leaders of the three countries extended their joint research on the CJK FTA to include industries, governments, and academia. However, such research efforts have generally focused on rationales for the trilateral FTA, not on agendas for actual negotiations. This suggests the likelihood of the delay of the negotiation conclusion, even when the countries can overcome political obstacles.

\section{Assessment of East Asian Economic Integration}

In recent years, East Asia has witnessed several new initiatives for regional economic integration in addition to many existing ASEAN+1 FTAs. In this regard, building a large trading bloc may be needed to realize economic gains and minimize economic losses from overlapping FTAs. The utilization ratio for ASEAN+1 FTAs is very low because market access allowed in ASEAN+1 FTAs is poor and the preferential margin is negligible.6) The Western literature has mentioned the Spaghetti Bowl effect as a reason for this low

6) According to Kawai and Wignaraja (2009), 28\% of 841 Asian firms sampled used the preferential tariff margin, which was much lower than the utilization ratio for E.U. and U.S. firms. 
utilization of preferential tariffs provided in FTAs. However, this does not apply to East Asia. The FTA preferential tariff margin was not being used because of small gains from the ASEAN-Korea FTA. Similar survey results have been found for ASEAN countries, Japan, and China. The rules for services, investment, and trade under those FTAs are based on ASEAN countries' existing WTO commitments, although negligible improvements are included. This raises the question of whether East Asian countries are ready to promote a region-wide and comprehensive FTA that eliminates tariffs.

ASEAN concluded bilateral FTAs with China, Japan, Korea, India, Australia, and New Zealand through ASEAN+1 FTAs, and the East Asian Summit (EAS) has been held on a regular basis since 2005. This suggests that the foundation for East Asian economic integration has progressed to some extent in that wide issues for region-wide economic integration have been discussed at various levels during meetings. In particular, unlike in the past, a large number of FTAs are being concluded, and many countries have improved their capacity to build a region-wide trade bloc and further East Asian economic integration. In this context, if there is a firm regional consensus on economic integration in the near future, East Asian countries should be better prepared for promoting it in a regional context, displaying a driving force.

However, China and Japan, which are the most powerful countries in East Asia from the economic or political perspective, are in conflict over many issues surrounding intra-regional economic integration, and their competition for leadership has intensified over time. Therefore, there has been no sign of a compromise for economic integration between them. In addition, the rough historical experience between the two countries, whose influence is no less than that of other factors in the region, has worked to strengthen their competitive consciousness, not to induce their cooperation on major issues.

In the process of European economic integration after World War II, France and Germany pursued aggressive cooperation to prevent war and push peace for security, and in doing so, they were successful in leading integration efforts, inducing participation by neighboring countries. In comparison to the European case, East Asia has faced considerable difficulty in overcoming its lack of leadership in the integration process.

\section{Small Economic Gains}

Over time, the regional scope of East Asian economic integration has not only widened but also become more ambiguous. The U.S. and Russia participated in the 2010 East Asian Summit, and therefore there was a considerable overlap between APEC countries and members of the East Asian Summit. The superimposed share of the members 
of these two organizations exceeded $90 \%$. On the other hand, regional membership coverage became more obscure. The U.S. and Russia participated in the East Asian Summit, but there was no discussion on the participation of Taiwan and Mongolia, which are located in East Asia. This suggests that the regional expansion under East Asian regionalism has been due more to political considerations than to economic issues.

The expectation of strong economic gains from the promotion of an FTA is a necessary, not sufficient, condition. This became part of the obstacle to the promotion of the FTAPP. The effect of East Asian economic integration with the U.S. has been estimated to be equal to that of the FTAAP because there is an overlap between a majority of members. This raises the question of whether a region-wide FTA can be promoted. Economic effects represent a necessary condition. For a large number of countries to promote regional economic integration, they must be confident about its economic effects, and leadership by key countries intending to promote economic integration can be critical. As discussed earlier, Southeast Asian countries have traditionally argued their role as the leader of any intra-regional economic cooperation and integration, but there is a limit to the region leading East Asian economic integration in several aspects. Given the present situation, ASEAN is likely to have difficulty coordinating various viewpoints of its members, which increased from 16 countries in 2005 to 18 in 2010.

To generate the impetus for promoting a region-wide FTA in East Asia, countries need to be confident about its economic gains. Because East Asia's initiatives for regional economic integration cover 16 to 18 countries, a simple calculation of economic effects of such a bloc can be complex. Previous studies of economic gains have been limited in that they have generally ignored currently implemented FTAs. As demonstrated by various research institutes focusing on the APEC FTA, a region-wide FTA tends to be substantial economic effects. The Korea Institute for International Economic Policy estimated that if the 21 APEC members promote the FTAAP, Korea's real GDP may increase by up to $2.99 \%$ because of trade liberalization, and if capital accumulation is considered, its GDP may increase by 3.92 9.47\% according to simulation scenarios. ${ }^{7)}$ However, such estimates tend to be overestimated because currently implemented FTAs are not taken into account. Cheong and Tongzon (2012) estimated the economic effects of the TPP and the RCEP by considering implemented FTAs and found them to be less than one fourth of existing estimates.

It is difficult to expect the promotion of a region-wide East Asian FTA in which there is no leadership but fierce competition. Strategically, it is necessary to organize a CJK FTA with a large economy in the region first to properly pursue East Asian economic

7) Refer to the Korea Institute for International Economic Policy (2009) for detailed information. 
integration. However, a trilateral FTA is promoted based on a bilateral FTA, ${ }^{8)}$ and in general, trilateral negotiations have to address more issues than bilateral ones, which makes negotiations more difficult. In addition, Korea does not take a positive view of an FTA with Japan because of many political and economic issues. Because Korea has already established a wide FTA network with the U.S. and the E.U.9) and is currently engaged in bilateral negotiations with China, Korea is not likely to accept a shallow FTA with Japan. Although Japan has made a definite commitment to conclude a high-level FTA including the agriculture sector, it may have difficulty in actively promoting a Japan-Korea FTA. Korea's industrial sector has objected to an FTA with Japan because a large number of small and medium-sized enterprises are likely to face considerable losses from a Korea-Japan FTA. Korea cannot expect economic gains from a Korea-Japan FTA unless Japan provides Korea with special considerations. This can be explained by data from the Korean government, which show a 2 3\% increase in GDP under the China-Korea FTA but only a $1 \%$ increase under the CJK FTA. ${ }^{10)}$ Noteworthy is that economic gains are less likely under the larger trading bloc composed of the three countries than under bilateral FTAs.

\section{Rising China's Presence}

The FTA domino theory suggests that Japan's position is similar to that of the U.K. in European integration while comparing China to France, which took the lead in the early years of European integration after World War II. In the 1960s, when France led the establishment of the European Economic Community (EEC), which became the basis for the current European Union, the U.K. established the European Free Trade Association (EFTA) to cope with France's leadership at that time. However, the U.K. joined the EEC under France's check with shame after withdrawing from the EFTA, which was weak in terms of the size and level of economic integration, and even today, the U.K. has failed to play a leading role in the E.U. In this regard, Baldwin stated that Japan is following the failure of the U.K.

East Asian economic integration in the form of a Japan-led ASEAN+6 FTA is likely to be further delayed, and China, which has perceived the ASEAN+6 system as a tool for

\footnotetext{
8) It can be argued that the negotiations for a trilateral FTA can be concluded more easily than bilateral FTAs in Northeast Asia because China, Japan, and Korea can complement one another in their trade and industrial structures.

9) Except for FTAs with ASEAN and India, most FTAs that Korea has concluded are evaluated to be of high quality in terms of market access and comprehensiveness.

10) For further details, see Cheong (2013).
} 
holding the country in check, is likely to focus on establishing an ASEAN+3 FTA by integrating bilateral FTAs with ASEAN and Korea after concluding its FTA negotiations with Korea. One of the factors influencing China's proactive attitudes toward an FTA with Korea may be its grand strategy for winning the competition for leadership in regional economic integration in East Asia. Although China has agreed to negotiate the CJK FTA, it is unclear whether the country would really promote it instead of considering it as a countermeasure against the RCEP initiative. If the CJK FTA is feasible within a reasonable period of time, then it is not necessary for China to promote an FTA with Korea. Japan may be reluctant in joining a China-led regional integration effort. Japan's participation is uncertain, but if a China-Korea-ASEAN FTA progresses, the country is very likely to participate in the bloc based on domino theory. This may be the strategy that China is implementing in a step-by-step manner.

As discussed earlier, China has already solidified its position for promoting an East Asian FTA while participating in the negotiations for the RCEP, but its efforts have been delayed because of the different position taken by Japan and a lack of a consensus in East Asia. China's intention to promote a China-Korea FTA is driven not only by the need to minimize economic losses from the Korea-U.S. FTA and the Korea-E.U. FTA but also by diverse intension such as the formation of a foundation for establishing a region-wide FTA and the strengthening of its leadership in East Asia, among others. According to Japan's strategy for holding China in check, as Australia, New Zealand and India joined the East Asian regionalism, followed by the participation of the U.S. and Russia in the East Asian Summit, the regional scope of East Asian economic integration has become ambiguous and similar as the APEC. In this regard, the future of the East Asian Summit is feared to rely on the present APEC Summit.

\section{Conclusion: Feasibility of a Large Trade Bloc in East Asia}

The ASEAN+3 Summit, sparked by the Asian financial crisis of 1997, was extended to include Australia, New Zealand, and India under the ASEAN+6 Summit in 2005, and the name was changed to the "East Asia Summit." This summit admitted additional members, namely the U.S. and Russia, since 2010. East Asia has institutionalized various forms of summit talks, but the major goals have not been clearly identified, although a series of statements has been issued after each summit. Regional economic integration has sometimes emerged as a primary goal, but ASEAN's strategic efforts to improve its leadership position have stood out. 
ASEAN countries have focused their energy on consolidating the existing ASEAN Free Trade Area (AFTA) for the ASEAN Economic Community (AEC). With the progress of the TPP since 2010, East Asia has faced a regional division into two groups - TPP participants and nonparticipants - which may weaken the ASEAN membership. Because the four ASEAN countries officially participate in TPP negotiations, ASEAN needs to introduce a new initiative for regional economic integration, although it cannot force these four countries to withdraw from the TPP. New East Asian economic integration agendas have developed into the RCEP. In addition, China, Japan, and Korea (representing Northeast Asia) have agreed to initiate negotiations for the CJK FTA, which has been discussed between the three countries for several years. ${ }^{11)}$

In East Asia, the AEC, the RCEP, and the CJK FTA may coexist or be promoted as major trading blocs in the future, and this may be regarded as an indication of the active promotion of regional integration. On the other hand, multilayered regionalism can be seen as some internal disorder. If ASEAN promotes the RCEP to cope with the TPP, then the RCEP should be a robust agreement, and ASEAN should be ready to lead the negotiations for a region-wide bloc. The AEC should be accomplished by ASEAN countries without delay. ${ }^{12)}$ If China, Japan, and Korea appreciate the value of the RCEP, then it is reasonable for them to avoid a trilateral FTA. ASEAN, which proposed the RCEP, has argued that ASEAN has to maintain its leadership position in regional economic integration based on ASEAN+1 FTAs, but if the CJK FTA forms, it is inevitable for ASEAN to lose its leadership in discussions on regional economic integration because of higher economic size and political power. Although East Asian countries appear to be working together, they each have different objectives and approaches with respect to region-wide economic integration. It is difficult to determine whether they would hold one another in check or whether there would be an RCEP for region-wide integration in which most countries participate under the domino effect of economic integration. In particular, AFTA-ASEAN centrality may not be compatible with the CJK FTA.

This casts doubt on the realization of the CJK FTA. To cope with the U.S.-led TPP and the RCEP (led by ASEAN and Japan), China has strongly requested Korea and Japan to initiate CJK FTA negotiations. Japan has been concerned about the emergence of China and its weakening leadership in East Asia. As a result, it once prioritized the CEPEA (ASEAN+6 FTA) over the East Asia FTA (ASEAN+3 FTA), which was advocated by China, but since then, it has emphasized economic integration through the RCEP, not

11) Various issues have been discussed by the Joint Study Committee for a FTA by China, Japan, and Korea. See the MOFAT (2011).

12) ASEAN delayed the target year for the AEC by a year in 2012, and given previous ASEAN agendas, the new target (the end of 2015) is expected to be extended again. 
through the CEPEA, in conjunction with ASEAN.

Because of the Japanese government's cabinet system and the strong lobby by the agricultural sector, Japan has had considerable difficulty overcoming its backwardness in terms of its FTA policy in comparison with China and Korea. Around the 2011 APEC Summit, the Noda government declared its participation in TPP negotiations, but because of strong opposition by the agricultural sector, it has not materialized. Although the government has released its plans for initiating FTA negotiations with the U.S. and the E.U. through various media channels, there has been no practical progress. To resume Japan-Korea FTA negotiations, which was suspended in late 2004, Japan has persuaded Korea's trade officials, but the likelihood of initiating negotiations with Korea remains low except for some working-level discussions between Japan and Korea for a number of years.

However, Japan's trade authorities have made multidimensional efforts to promote East Asian economic integration to be compatible with Japan's national trade agenda while coping with the emergence of China's leadership. At the 15th ASEAN+3 Summit in Phnom Penh on November 10, 2012, the Japanese trade authorities achieved some success. Using the RCEP, which can be perceived as including something recondite, even though the name is unfamiliar, they may politically overcome the TPP issue, which has become controversial in the last few years. This means the Japanese government has succeeded in establishing a foundation for taking the initiative in the RCEP such that their policy, not the U.S.-led TPP, is reflected. In addition, the CJK FTA can provide Japan with additional gains. The fact that Japan has come to begin FTA negotiations with Korea can substitute for the interrupted Japan-Korea FTA, and the China-led CJK FTA, like fishing in troubled waters, is likely to provide Japan with a chance for a FTA with Korea.

The CJK began the negotiation for the CJK FTA in Seoul March 2013. It may be difficult for them to reach an agreement in a short period of time (e.g., three years). That is, it may take at least five years. It is difficult to be optimistic about whether the Japanese authorities can negotiate an FTA with China because Japan is likely to have considerable difficulty overcoming opposition from the agricultural sector, despite Japanese trade authorities' position that they cannot avoid an FTA with China in coping with the negotiation for the China-Korea FTA negotiations. This implies that the CJK FTA may become a shallow agreement that just saves the three countries from embarrassment regardless of the content of the agreement under plausible conditions after a number of negotiations. 


\section{References}

Armstrong, Shiro. 2011, The TPP, APEC and East Asian trade strategies, East Asia Forum, November 13, available at www.eastasiaforum.org

Bergsten, C. Fred. 1997, Open Regionalism, Working Paper 97-3, Washinton D.C.: Peterson Institute for International Economics

Cheong, Inkyo and Jose Tongzon. 2012, "Net Impact of the TPP and the RCEP: An Analysis Using a Dynamic CGE Model", presented at the AEP conference (October, Keio University)

Cheong, Inkyo. 2013, "Japan's role in the progress of the RCEP," Short Essay, Seoul: KERI.

Drysdale, Peter. 2010, “APEC's Achievements and Challenges Today”, Paper presented at APEC Growth Strategy High-Level Policy Round Table, Beppu, Japan, August 7-8, 2010

East Asian Vision Group. 2001, Towards an East Asian Community.

Elek, Andrew, (2010) Towards a single market: a twenty-first century vision for the Asia Pacific, Koreas Institute of International Economic Policy, Seoul, March.

Garnaut, Ross. 1994, "Open Regionalism: Its Analytic Basis and Relevance to the International System.” Journal of Asian Economics 5, no. 2 (Summer): 273-90.

Garnaut, Ross. 1996, Open Regionalism and Trade Liberalisation: An Asia-Pacific Contribution to the World Trade System, Allen and Unwin/Institute of Southeast Asian Studies.

Kawai, Masahiro and Ganeshan Wignaraja. 2009, "The Asian ""Noodle Bowl”": Is It Serious for Business? ADBI Working Paper Series.

Korea Institute for International Economic Policy. 2009, "FTAAP's Economic Effect \& its Ripple Effect on Korea." Seoul: KIEP

MOFAT. 2011, Joint Study Report for an FTA among China, Japan, and Korea, Seoul, Korea: MOFAT, December 16

Sutton, Michael. 2007, Open Regionalism and the Asia Pacific: Implications for the Rise of an East Asian Economic Community. Institute of International Relations and Area Studies, Ritsumeikan University 